DOI: $10.17148 /$ IARJSET.2022.9125

\title{
Metacognition and Scholastic Performance of Higher Secondary School Students: A Correlational Analysis
}

\author{
Sathish $\mathbf{K}^{1}$, Dr. A. Subramanian ${ }^{2}$ \\ ${ }^{1} \mathrm{Ph} . D$. Scholar, Department of Education, University of Madras, Chennai - 600005, Tamil Nadu \\ ${ }^{2}$ Assistant Professor, Head i/c, Department of Education, University of Madras, Chennai - 600005, Tamil Nadu
}

\begin{abstract}
The study was conducted to explore the levels of Metacognition and Scholastic Performance of higher secondary school students; and also to find out the relationship between Metacognition and Scholastic Performance of higher secondary school students. The relative contribution of personal variables such as Gender and Locality of the students were also studied. Survey method was adapted for the study and a sample of 110 higher secondary school students were selected by random sampling. Metacognition scale consisting of 24 items was employed to assess Metacognition among the students. The collected data were subjected to differential and correlational analysis. The results of differential analysis showed that (i) Girls have more Metacognition and better Scholastic Performance than boys: and (ii) Urban students have more Metacognition as well as better Scholastic Performance than Rural students. The results of correlational analysis showed that there is a significantly Positive Relationship between Metacognition and Scholastic Performance.
\end{abstract}

Keywords: Metacognition, Metacognitive Awareness, Metacognitive Regulation, Metacognitive Experience, Scholastic Performance.

\section{INTRODUCTION}

The generation of new information/knowledge is accelerating at a rapid pace. It is widely felt that individual differences among students are so extreme and unique, each have a different ways of processing information. It is high time that the students are developing the abilities to introspect their mental processes along with learning the curriculum. An extensive knowledge about an individual's thinking processes facilitates learning and bring about better scholastic performances.

\section{METACOGNITION}

The term Metacognition was first put forth by Flavell, (1979). According to him, metacognition is the "knowledge and cognition about cognitive phenomena". Metacognition can be simply stated as the process of thinking about thinking. Schraw and Moshman, (1995) describes it as an individual's ability to know and regulate the cognitive process. Another definition of metacognition was given by Ormond, (2006) as the knowledge and application of cognitive processes for learning.

Vukman, (2005) conceptualized that the cognitive complexity and metacognition are interrelated with each other. Individuals who has more complex thought processes tend to have higher levels of metacognitive skills (Swanson \& Hill, 1993).

Metacognition has three components, namely, Metacognitive Awareness, Metacognitive Regulation and Metacognitive Experience. Schraw and Dennison, (1994) describes that these components are interrelated with each other.

\subsection{Metacognitive Awareness}

Metacognitive awareness can be stated as an individual's knowledge about his/her cognitive processes. It includes a person's beliefs and differences, the knowledge of factors that can have influencing effect on learning; the knowledge about the requirements for learning different things; awareness about various strategies for learning; the ability to adopt a specific strategy for learning specific things.

\subsection{Metacognitive Regulation}

Metacognitive regulation can be stated as the activities of an individual that can influence his/her learning (Schraw and Moshman, 1995). It involves three components, viz., planning, monitoring and evaluating. Planning is concerned with identifying the learning objectives, setting up goals and utilizing the necessary strategies and cognitive resources before taking up a learning task. Monitoring is concerned with tracking the progress of learning and being aware of what needs to be done to achieve the goals. Evaluating is concerned with checking whether the learning objectives are met by the learning outcomes. 


\section{International Advanced Research Journal in Science, Engineering and Technology \\ Impact Factor $7.105 \div$ Vol. 9, Issue 1, January 2022 \\ DOI: 10.17148/IARJSET.2022.9125}

\subsection{Metacognitive Experience}

Metacognitive experience is defined as the affective experiences an individual go through while learning. It can lead to new knowledge, abandoning or revising and correcting the existing knowledge.

\section{NEED AND SIGNIFICANCE OF THE STUDY}

Learning process involves higher levels of intellectual functioning as well as the ability to plan, execute and evaluate the learning activity. Metacognition plays avital role in learning as it involves almost all the necessary skills required for performing a learning task to the utmost level. Many researchers examined and reported that there exist relationships between metacognition and scholastic performances. Everson \& Tobias (1998) the students demonstrating high levels of metacognitive ability were linked with higher grade point average. Coutinho, S. (2007) reported that the students with high level of metacognitive skills have high academic achievement. On the contrary, Justice and Dorran, (2001) reported that the metacognition and academic achievement were negatively correlated. Cubukcu (2009) conducted an experiment and found out that using metacognitive strategies did not have an effect on students' achievement. As metacognition have greater influence on scholastic performance it is felt important to study these variables among the higher secondary schools students. Hence the present study aims to assess the Metacognition among higher secondary school students and also to find out the relationship between Metacognition and Scholastic Performance of higher secondary school students.

\section{OBJECTIVES OF THE STUDY}

1. To study the Metacognition and Scholastic Performance of the higher secondary school students.

2. To study whether there is any significant difference in Metacognition and Scholastic Performance of the students with respect to the Gender and Locality of the higher secondary school students.

3. To study whether there is any significant relationship between Metacognition and Scholastic Performance of higher secondary school students.

\section{HYPOTHESES OF THE STUDY}

1. There is no significant difference in Metacognition of the higher secondary school students with respect to their Gender.

2. There is no significant difference in Scholastic Performance of the higher secondary school students with respect to their Gender.

3. There is no significant difference in Metacognition of the higher secondary school students with respect to their Locality.

4. There is no significant difference in Scholastic Performance of the higher secondary school students with respect to their Locality.

5. There is no significant relationship between Metacognition and Scholastic Performance of the higher secondary school students.

\section{METHOD OF THE STUDY}

The present study is specially intended to assess the levels of Metacognition and Scholastic Performance of the higher secondary school students and also attempts to find the relationship between them. As the present research is concerned about studying the interrelationship of the research variables in their existing condition in the population, it is bound to follow 'Survey method'.

\section{POPULATION AND SAMPLE}

The Population of the study comprises of all the higher secondary school students studying in Vellore District of Tamil Nadu. By adopting the Random Sampling technique, 110 higher secondary school students, who volunteered to be participants for the present study were chosen as the sample for data collection.

\section{TOOLS USED FOR COLLECTION OF DATA}

The Metacognition Scale developed and validated by the researchers was used for the study. It is a 3 points Likert type scale, consisting of 24 items. It is divided into three factors or dimensions of Metacognition namely, Metacognitive Awareness, Metacognitive Regulation and Metacognitive Experience. Each of these three categories is represented by 8 items. In order to establish reliability, Cronbach Alpha coefficient was calculated for the Metacognition Scale and it was 


\section{International Advanced Research Journal in Science, Engineering and Technology \\ Impact Factor $7.105 \div$ Vol. 9, Issue 1, January 2022 \\ DOI: $10.17148 /$ IARJSET.2022.9125}

found out to be 0.806 . The validity of the scale was established by calculating the square root of reliability coefficient and it was found out to be 0.898 . Hence the tool is reliable and valid. Percentage of marks secured by the students in their board examinations were taken as scores of Scholastic Performance. The tool was administered with personal data sheet to all the participants and the data were collected.

\section{RESULTS AND INTERPRETATION}

\subsection{Results based on Descriptive Analysis}

\section{Table 1}

Mean and Standard Deviation of Metacognition and Scholastic Performance for Entire Sample.

\begin{tabular}{|l|l|l|l|}
\hline Variables & Mean & Standard Deviation & Mean Percentage \\
\hline Overall Metacognition & 47.95 & 5.824 & 66.60 \\
\hline Metacognitive Awareness & 17.09 & 2.663 & 71.21 \\
\hline Metacognitive Regulation & 15.54 & 4.002 & 64.75 \\
\hline Metacognitive Experience & 15.33 & 2.343 & 63.86 \\
\hline Scholastic Performance & 68.74 & 16.25 & 68.74 \\
\hline
\end{tabular}

The results shown in the Table 1 indicates that the Mean value, Standard Deviation value and Mean Percentage of Metacognition, Metacognitive Awareness, Metacognitive Regulation, Metacognitive Experience and Scholastic Performance for the entire sample.

\subsection{Results based on Differential Analysis}

\section{Table 2}

Sample Descriptives Using t-test for Equality of Means with respect to Gender

\begin{tabular}{|c|l|l|l|l|l|l|}
\hline \multirow{2}{*}{ Variables } & \multicolumn{2}{|l|}{ Boys } & \multicolumn{2}{l|}{ Girls } & \multirow{2}{*}{ t-value } & p-value \\
\cline { 2 - 7 } & Mean & S.D & Mean & S.D & & \\
\hline Metacognition & 45.88 & 5.091 & 51.44 & 3.690 & 5.431 & $\mathrm{p}<0.01$ \\
\hline Metacognitive Awareness & 18.42 & 2.234 & 14.85 & 1.662 & 8.874 & $\mathrm{p}<0.01$ \\
\hline Metacognitive Regulation & 13.04 & 2.563 & 19.73 & 1.925 & 14.452 & $\mathrm{p}<0.01$ \\
\hline Metacognitive Experience & 14.42 & 2.230 & 16.85 & 1.652 & 6.076 & $\mathrm{p}<0.01$ \\
\hline Scholastic Performance & 65.81 & 16.032 & 73.69 & 15.591 & 2.524 & $\mathrm{p}<0.05$ \\
\hline
\end{tabular}

*S.D - Standard Deviation

From the results shown in the Table 2, it may be clear that the p-value of Metacognition and its three dimensions is lesser than 0.01, therefore the null hypothesis is rejected. Hence it can be concluded that the Boys and Girls did differ significantly in Metacognition and its three dimensions at 0.01 level of significance.

The mean value of Metacognition shows that girls have more Metacognition than boys at 0.01 level of significance.

The mean value of Metacognitive Awareness shows that, boys have more Metacognitive Awareness than girls at 0.01 level of significance.

The mean value of Metacognitive Regulation and Metacognitive Experience shows that girls have better Metacognitive Regulation and Metacognitive Experience than boys at 0.01 level of significance.

The p-value of Scholastic Performance is lesser than 0.01, therefore the null hypothesis is rejected. Hence it can be concluded that the Boys and Girls did differ significantly in Scholastic Performance at 0.05 level of significance. Moreover, the mean value of Scholastic Performance shows that girls have better Scholastic Performance than boys at 0.05 level of significance.

Table 3

Sample Descriptives Using t-test for Equality of Means with respect to Locality

\begin{tabular}{|c|l|l|l|l|l|l|}
\hline \multirow{2}{*}{ Variables } & \multicolumn{2}{l|}{ Rural } & \multicolumn{2}{l|}{ Urban } & \multirow{2}{*}{ t-value } & \multirow{2}{*}{ p- value } \\
\cline { 2 - 7 } Metacognition & Mean & S.D & Mean & S.D & & \\
\hline Metacognitive Awareness & 46.78 & 6.195 & 49.64 & 4.820 & 2.598 & $\mathrm{p}<0.01$ \\
\hline Metacognitive Regulation & 17.86 & 2.752 & 15.98 & 2.098 & 3.875 & $\mathrm{p}<0.01$ \\
\hline
\end{tabular}




\section{International Advanced Research Journal in Science, Engineering and Technology \\ Impact Factor 7.105 $\div$ Vol. 9, Issue 1, January 2022 \\ DOI: 10.17148/IARJSET.2022.9125}

\begin{tabular}{|l|l|l|l|l|l|l|}
\hline \multicolumn{1}{|c|}{ Metacognitive Experience } & 14.97 & 2.436 & 15.84 & 2.132 & 1.951 & $\mathrm{p}>0.05$ \\
\hline Scholastic Performance & 66.26 & 16.773 & 72.34 & 14.930 & 1.994 & $\mathrm{p}<0.05$ \\
\hline
\end{tabular}

*S.D - Standard Deviation

From the results shown in the Table 3, it may be clear that the p-value of Metacognition and two of its dimensions namely, Metacognitive Awareness and Metacognitive Regulation is lesser than 0.01, therefore the null hypothesis is rejected. Hence it can be concluded that the Rural students and Urban students did differ significantly in Metacognition and two of its dimensions at 0.01 level of significance.

The mean value of Metacognition shows that Urban students have more Metacognition than Rural students at 0.01 level of significance.

The mean value of Metacognitive Awareness shows that, Rural students have more Metacognitive Awareness than Urban students at 0.01 level of significance.

The mean value of Metacognitive Regulation shows that Urban students have better Metacognitive Regulation than Rural students at 0.01 level of significance.

The p-value of Scholastic Performance is lesser than 0.05, therefore the null hypothesis is rejected. Hence it can be concluded that the Rural students and Urban students did differ significantly in Scholastic Performance at 0.05 level of significance. Moreover, the mean value of Scholastic Performance shows that Urban students have better Scholastic Performance than Rural students at 0.05 level of significance.

\subsection{Results based on Correlation Analysis}

\section{Table 4}

Pearson's Correlation coefficient between Metacognition and Scholastic Performance.

\begin{tabular}{|c|l|l|l|l|l|}
\hline Variables & $\mathbf{1}$ & $\mathbf{2}$ & $\mathbf{3}$ & $\mathbf{4}$ & $\mathbf{5}$ \\
\hline Metacognition & - & & & & \\
\hline Metacognitive Awareness & $0.401 * *$ & - & & & \\
\hline Metacognitive Regulation & $0.768 * *$ & $-0.249 * *$ & - & & \\
\hline Metacognitive Experience & $0.941 * *$ & $0.429 * *$ & $0.621 * *$ & - & \\
\hline Scholastic Performance & $0.610 * *$ & $0.360 * *$ & $0.442 * *$ & $0.499 * *$ & - \\
\hline
\end{tabular}

** Correlation is significant at the 0.01 level (2-tailed).

Note: The correlation co-efficient value (r-value) were shown below the diagonal.

The result shown in the Table 4 indicates that the p-value for the correlation of Metacognition and Scholastic Performance is lesser than 0.01, therefore the null hypothesis is rejected. Hence there is a significant relationship between Metacognition and Scholastic Performance at 0.01 level of significance.

The r-value between Metacognition and Scholastic Performance was found to be $r=0.610$. Therefore it can be stated that there is significant positive relationship between Metacognition and Scholastic Performance at 0.01 level of significance. There is significant positive relationship $(\mathrm{r}=0.360)$ between Metacognitive Awareness and Scholastic Performance even at 0.05 level of significance.

There is low positive relationship $(r=0.442)$ between Metacognitive Regulation and Scholastic Performance at 0.05 level of significance.

There is moderate positive relationship $(\mathrm{r}=0.499)$ between Metacognitive Experience and Scholastic Performance at 0.01 level of significance.

\section{Table 5}

Pearson's Correlation coefficient between Metacognition and Scholastic Performance with respect to Gender

\begin{tabular}{|c|l|l|l|l|l|}
\hline Variables & $\mathbf{1}$ & $\mathbf{2}$ & $\mathbf{3}$ & $\mathbf{4}$ & $\mathbf{5}$ \\
\hline Overall Metacognition & - & 0.159 & $.756^{* *}$ & $.912^{* *}$ & $.683^{* *}$ \\
\hline Metacognitive Awareness & $.496^{* *}$ & - & $-.486^{* *}$ & 0.15 & $.387^{*}$ \\
\hline Metacognitive Regulation & $.779 * *$ & -0.135 & - & $.593^{* *}$ & $.424^{* *}$ \\
\hline Metacognitive Experience & $.951^{* *}$ & $.548^{* *}$ & $.633^{* *}$ & - & $.479^{* *}$ \\
\hline Scholastic Performance & $.589^{* *}$ & $.354^{* *}$ & $.451^{* *}$ & $.510^{* *}$ & - \\
\hline
\end{tabular}

** Correlation is significant at the 0.01 level (2-tailed).

* Correlation is significant at the 0.05 level (2-tailed).

Note: The correlation co-efficient value ( $\mathrm{r}$ - value) of girls and boys were shown above and below the diagonal respectively. 


\section{International Advanced Research Journal in Science, Engineering and Technology \\ Impact Factor $7.105 \div$ Vol. 9, Issue 1, January 2022 \\ DOI: 10.17148/IARJSET.2022.9125}

The result given in the Table 5, shows that the $r$ - value of Metacognition and Scholastic Performance of boys was 0.589 . Hence, there is significant moderate positive relationship between Metacognition and Scholastic Performance of boys studying in higher secondary school at 0.01 Level of Significance.

It also shows that the $r$ - value of Metacognition and Scholastic Performance of girls was 0.683. Hence, there is significant moderate positive relationship between Metacognition and Scholastic Performance of girls studying in higher secondary school at 0.01 Level of Significance.

Table 6

Pearson's Correlation coefficient between Metacognition and Scholastic Performance with respect to Locality

\begin{tabular}{|l|l|l|l|l|l|}
\hline Variables & $\mathbf{1}$ & $\mathbf{2}$ & $\mathbf{3}$ & $\mathbf{4}$ & $\mathbf{5}$ \\
\hline Overall Metacognition & - & 0.166 & $.794 * *$ & $.942^{* *}$ & $.626^{* *}$ \\
\hline Metacognitive Awareness & $.548^{* *}$ & - & $-.443^{* *}$ & 0.192 & $.417 * *$ \\
\hline Metacognitive Regulation & $.754^{* *}$ & -0.103 & - & $.669^{* *}$ & $.352^{*}$ \\
\hline Metacognitive Experience & $.939^{* *}$ & $.578^{* *}$ & $.586^{* *}$ & - & $.522^{* *}$ \\
\hline Scholastic Performance & $.614^{* *}$ & $.332^{* *}$ & $.518^{* *}$ & $.499^{* *}$ & - \\
\hline
\end{tabular}

** Correlation is significant at the 0.01 level (2-tailed).

* Correlation is significant at the 0.05 level (2-tailed).

Note: The correlation co-efficient value (r-value) of Urban and Rural students were shown above and below the diagonal respectively.

The result given in the Table 6, shows that the $r$ - value of Metacognition and Scholastic Performance of rural students was 0.614 . Hence, there is significant moderate positive relationship between Metacognition and Scholastic Performance of rural students studying in higher secondary school at 0.01 Level of Significance.

It also shows that the $\mathrm{r}$ - value of Metacognition and Scholastic Performance of urban students was 0.626. Hence, there is significant moderate positive relationship between Metacognition and Scholastic Performance of urban students studying in higher secondary school at 0.01 Level of Significance.

\section{MAJOR FINDINGS}

i. Girls (51.44) have more Metacognition than boys (45.88) at 0.01 level of significance.

ii. Girls (73.69) have better Scholastic Performance than boys (65.81) at 0.05 level of significance.

iii. Urban students (49.64) have more Metacognition than Rural students (46.78) at 0.01 level of significance.

iv. Urban students (72.34) have better Scholastic Performance than Rural students (66.26) at 0.05 level of significance.

v. There is significant positive relationship $(\mathrm{r}=0.610)$ between Metacognition and Scholastic Performance at 0.01 level of significance.

\section{CONCLUSION}

The process of learning in a classroom context or in open life situation is characterized by an individual's nature and thought process. The activities by teacher in the classroom are to direct and stimulate student-learning. Students learn by using their individualized preferences in learning. There is significant positive relationship between Metacognition and Scholastic Performance, therefore it is necessary for the teacher to impart the importance of Metacognition in learning outcomes. Moreover, teaching to develop metacognitive skills among the students will result in them becoming better learners (Zimmerman \& Schunk, 2001). Developing metacognitive skills is not confined only to better academic results but also to demonstrate better decision making after their academic careers.

\section{REFERENCES}

[1] Coutinho, S. "The Relationship between goals, Metacognition, and Academic success.” Educate Journal, vol. 7, no. 1, pp. 39- 47. 2007.

[2] Cubukcu, F. "Metacognition in the classroom." Procedia social and behavioral science, vol. 1, pp. 559-563. 2009.

[3] Everson, H. and Tobias, S. "The ability to estimate knowledge and performance in college: A metacognitive analysis." Instructional Science, vol. 26, pp. 65-79. 1998.

[4] Flavell, J. H. "Metacognition and cognitive monitoring: A new area of cognitive-developmental inquiry." American Psychologist, vol. 34, no. 10, pp. 906-911. 1979.

[5] Justice, E.M. and Dornan, T.M. "Metacognitive differences between traditional-age and nontraditional - age college students." Adult education quarterly, vol. 51, pp. 236-249. 2001.

[6] Ormond, J. E. "Educational Psychology: Developing Learners” (5th ed). Upper Saddle River, NJ: Pearson Education, Inc. 2006. 
International Advanced Research Journal in Science, Engineering and Technology

Impact Factor 7.105 Vol. 9, Issue 1, January 2022

DOI: 10.17148/IARJSET.2022.9125

[7] Schraw, G. and Dennison, R. S. “Assessing metacognitive awareness.” Contemporary Educational Psychology, vol. 19, pp. 460-475. 1994.

[8] Schraw, G. and Moshman, D. "Metacognitive Theories.” Educational Psychology Review, vol. 7, pp. 351-373. 1995.

[9] Swanson, L., and Hill, G. "Metacognitive aspects of moral reasoning and behavior." Adolescence, vol. 28, pp. 711735. 1993.

[10] Vukman, K. B. "Developmental differences in metacognition and their connections with cognitive development in adulthood." Journal of Adult Development, vol. 12, no. 4, pp. 211-221. 2005.

[11] Zimmerman, B. J., and Schunk, D. H. "Reflections on theories of self-regulated learning and academic achievement." Theoretical perspectives, pp. 289-307. 2001. 